\title{
Coronavirus Disease 2019, School Closures, and Children's Mental Health
}

\author{
Geon Ho Bahn \\ Department of Psychiatry, Kyung Hee University School of Medicine, Seoul, Korea
}

Coronavirus disease 2019 (COVID-19), which was first identified in Wuhan, China, in late December of 2019 is rapidly spreading across the globe. The South Korean government has ordered the closure of all schools, as part of its attempts to use social distancing measures to prevent the spread of COVID-19. The effects of the school closures on reducing contagion are generally positive; however, the measure is controversial because of the socioeconomic ripple effect that accompanies it. The author briefly reviewed the existing literature on the mental health aspects of disasters and presents the issues related to school closures due to pandemics, from medical and socioeconomic perspectives and in terms of children's mental health. The results of this review suggest that research on children's mental health in relation to the adoption of school closures as a pandemic mitigation strategy is urgently needed.

Key Words: Coronavirus disease 2019; COVID-19; School closures; Children; Mental health; Economy; Pandemic; Resilience.

Received: March 9, 2020 / Revised: March 13, 2020 / Accepted: March 16, 2020

Address for correspondence: Geon Ho Bahn, Department of Psychiatry, Kyung Hee University School of Medicine, 23 Kyungheedae-ro, Dongdaemungu, Seoul 02447, Korea

Tel: +82-2-958-8542, Fax: +82-2-957-1997, E-mail: mompeian@khu.ac.kr

\section{INTRODUCTION}

A cluster of pneumonia cases of unknown origin from Wuhan, Hubei Province, was reported to the China National Health Commission on December 30, 2019 [1]. One week later, Chinese scientists had isolated a novel coronavirus from these patients. The report of a novel coronavirus outbreak was published online by The Lancet on January 24, 2020. According to the report, new patients from countries other than China, such as Thailand, Korea, and Japan, had been confirmed as having coronavirus disease 2019 (COVID-19) [1]. The number of confirmed cases has increased exponentially, and new cases have been reported worldwide [2]. Based on past research on the severe acute respiratory syndrome (SARS) epidemic of 2003 [3] and the Middle East respiratory syndrome coronavirus (MERS-CoV) epidemic of 2012 to 2015 [4], which were both types of coronavirus, it can be surmised that COVID-19 affects not only physical disabilities but also mental health [5]. While there have been several reports on the mental health problems faced by medical workers in Wuhan (such as stress, anxiety, depressive symptoms, insomnia, denial, anger, and fear) [6], the mental health problems of the patients with COVID-19 have yet to be thoroughly investigated [7].

This is an Open Access article distributed under the terms of the Creative Commons Attribution Non-Commercial License (https://creativecommons.org/licenses/by-nc/4.0) which permits unrestricted non-commercial use, distribution, and reproduction in any medium, provided the original work is properly cited.
Furthermore, countermeasures employed by American [8], Chinese [5], and Korean psychiatrists [9] have been found to be insufficient to predict or resolve these mental health problems, especially those of infants, children, and adolescents.

School closure, a social distancing strategy, is considered to effectively reduce community transmission [10]. As the COVID-19 outbreak enters its third month, the ministry of education in Korea has postponed the new school year from the first of March to 3 weeks later for kindergarten, elementary, middle, and high schools across the country. All colleges and universities have also decided to postpone the beginning of the new semester for 2 weeks or more. Most childcare centers nationwide have been closed indefinitely for several weeks. With schools and institutions shutdown, the author, as one of the professionals in the field of children's mental health, is not only deeply concerned about the COVID-19 outbreak, but also about the mental health of our children. How will the prolonged epidemic and school closures affect children's mental health? How should mental health professionals prepare and for what? What should be our focus if the disaster continues for longer than we expect?

Although an examination of all obstacles and possible solutions may not be possible at the moment, this study reviewed the existing literature for methods (even temporary or incomplete ones) to address children's mental health issues that are related to the COVID-19 outbreak and resultant school closures. 


\section{MENTAL HEALTH PERSPECTIVES ON DISASTERS}

The disasters and stressors experienced by humans include life/developmental stressors, such as parental divorce or vehicle accidents, human-generated acts of violence, such as rape or war, and natural disasters, such as earthquakes or pandemics [11]. Studying previous disasters can help us prepare for new ones, even in the types of disasters are different from one another.

The 9/11 attacks (an example of human-generated acts of violence) were a one-time planned attack that was traumatizing to many people, both directly and indirectly. In a child psychopathology study with students, conducted 6 months after $9 / 11$ [12], it was found that children of parents who lost their jobs or were restricted in their travel after 9/11, were likely to experience posttraumatic stress disorder or other anxiety disorders. Experiences of disaster-related adversity extend beyond traumatic exposure and include the long-term ripple effects of post-disaster life issues and economic difficulties. Therefore, mental health services that focus on the impact of disasters on students' lives are needed. One study conducted 2 to 3 years after the 9/11 attacks, on adolescents and family members, found that minority, low-income, and single-parent adolescents were the most affected groups [13]. If both the parents and their children are likely to develop post-disaster mental health symptoms, the official in charge should be particularly concerned.

During the SARS outbreak, mild to serious psychiatric symptoms were reported: patients diagnosed with SARS experienced anxiety, loneliness, boredom, anger, and worry about the effects of quarantine and contagion on family members and friends; medical staff experienced fear of contagion and of infecting others; and uncertainty and stigmatization was experienced by both staff and patients [14]. The human immunodeficiency virus/acquired immunodeficiency syndrome (HIV/AIDS) pandemic evolved to become the second leading cause of disability and the fourth leading cause of mortality worldwide by the end of the 20th century [11]. The results from a review of published papers on HIV/AIDS suggest that mental health professionals are in a unique position to adapt and apply the strategies that they use to treat psychiatric symptoms to prevent engagement in HIV transmission behaviors and, therefore, play a critical role in curbing the epidemic [15].

Mental health professionals in China have developed COVID-19 outbreak countermeasures for patients, their families, and medical staff based on methods used in the SARS outbreak [5]: first, mental health support should be provided by multidisciplinary mental health teams that have been es- tablished by health authorities at regional and national levels. Second, there must be clear communication and regular and accurate updates about the COVID-19 outbreak, in order to reduce the sense of uncertainty and fear. Third, services to provide psychological counselling using secure electronic devices and applications must be available. Fourth, patients who have experienced disasters should be screened regularly for depression, anxiety, and suicidality. If necessary, personalized psychiatric treatment that has been specifically tailored for the individual patient, including psychotherapy and psychotropic medication, should be provided [5]. Phone counselling should be employed because face-to-face therapy and interviews with play therapy are to be avoided due to the possibility of infection. Therefore, it is necessary to develop programs that use the internet and smartphones, and social workers, family therapists, pediatricians, and community-related agencies, as well as psychiatrists, should be required to undergo training on these programs [16].

\section{MEDICAL PERSPECTIVES OF SCHOOL CLOSURES}

When pandemic infectious diseases occur, school closures are a social distancing measure that is often conducted to reduce their impact [17]. However, there is little data on the short- and long-term consequences. The effects may vary depending on the timing of the closure decision and regional consistency. Non-pharmacological interventions, including school closures, church closures, the banning of mass gatherings, mandated mask wearing, isolation, and disinfection and hygiene measures were implemented during the Spanish Influenza of 1918 to 1919 in the United States. These interventions were determined in the early stages of the epidemic and implemented for a long time [10]. They had a moderate effect on the total mortality rate (perhaps reducing mortality by 10-30\%), and contributed greatly to the peak mortality reduction (around 50\% in some cities) [10]. Public health measures, including school closures, implemented in Sydney, Australia, in 1918 might have reduced cumulative attack rates during the influenza pandemic by up to $38 \%$ [18]. During the 1957-1958 Asian flu pandemic, closing schools and keeping children and teenagers at home contributed to a reduction of the attack rate by over 90\% [19]. In the case of SARS in Hong Kong, in 2003, government mandates and public concern resulted in considerably lower levels of confirmed influenza compared with the preceding five years [20]. Interventions such as school closures, banned mass gatherings, mask wearing in public, and staying at home as much as possible worked well.

A large-scale survey of eight different European countries conducted to determine the basic reproduction number on 
weekdays versus weekends and during regular versus holiday periods, found that school closures can have a substantial impact on the spread of a newly emerging infectious disease that is transmitted via non-sexual close contacts [21]. With the first case of H1N1 flu on May 11, 2009, the governor of Osaka, Japan, decided to close all 270 high schools and 526 junior high schools in Osaka Prefecture from Monday, May 18, to Sunday, May 24, following the weekend days of May 16 and 17 observed at most schools [22]. The prefecture-wide school closure strategy might have had an effect on the reduction of virus transmission and elimination of successive large outbreaks. In addition, it resulted in greater public awareness about the need for preventive measures. In Alberta, Canada, school closure reduced transmission of pandemic influenza (pH1N1) among students by more than $50 \%$, and this was a key factor in interrupting transmission in countries with social contact networks similar to those in Canada [23].

Results of a household survey conducted in China on the socio-economic impact and inconveniences of school closures due to the 2009 influenza A (H1N1) pandemic indicated that the majority (73\%) of families supported the policy despite economic inconvenience [24]. In a small, rural community in North Carolina in the United States, 91\% of households were in favor of school closures as a community mitigation strategy against the outbreak of influenza B [25].

In contrast, late or delayed decisions to close schools can be ineffective, as was the case in France during the 1957 pandemic [10]. At that time, public health officials were concerned that early school closures could increase public anxiety and create a sense of crisis. The decision was delayed until after $50-75 \%$ of children had fallen ill. Rodriguez et al. [26] examined the hypothesis that school closures during an influenza outbreak would result in lower absenteeism after the return to school. In 2007, among 470 schools in King County, Washington, in the United States, 265 closed during a seasonal influenza outbreak, while 205 remained in session. There was no significant difference in post-break absenteeism between the schools that had closed and those that remained in session. One study in Singapore [27] investigated the 1) public holiday effect, 2) school vacation effect, and 3) school closure during outbreaks effect on hand, foot, and mouth disease (HFMD) transmission with a large sample, for several years. While the results of that study provided evidence that school closure reduces HFMD transmission [27], the effect was small. Given the mild and self-limiting cases of HFMD and large burden following a school closure, the evidence from these reports suggests that policy makers should weigh very carefully whether the effect (particularly, the economic burden on families) of school closures for the mitigation of a pandemic is tolerable before deciding to implement them.
Although the infectious and latent periods of COVID-19 are not yet known [28], one study reports that the appropriate control measures for the disease include a quarantine and an observation period of 14 days for suspected cases, based on a mean incubation period of 5.2 days, with the 95th percentile of the distribution at 12.5 days [29]. One of the questions associated with school shutdown is when to reopen the schools.

\section{SOCIOECONOMIC PERSPECTIVES OF SCHOOL CLOSURES}

Deciding on whether or not to close schools, one of the main factors to consider is the economic impact on the households involved and on society [30]. When schools are closed, parents who have to go to work should quickly find people or facilities to take care of their children. Otherwise, it is inevitable that the child stays at home alone [10]. Generally, institution closings are a more serious and urgent issue for parents of toddlers and kindergarteners, than they are for parents of elementary, middle, and high school students [31]. Kids attending such programs are too young to help themselves, and, therefore, one of the parents has to work less or even has to quit his or her job when the institution closes, which will most likely result in the family experiencing economic difficulties [31]. After the closing of childcare centers, parents who work need different sources of care for their children. Studies suggest that respiratory infection rates are lower in childcare groups with less than six children [32]. It is very difficult to find such facilities at a time when the institutions are shut down because of a pandemic. In response of COVID-19 outbreak, the Korean government has developed nationwide emergency child care programs for parents who need child care support because of extended closures at child care centers, kindergarten schools, and elementary schools [33].

In addition, for low-income households or for families in which the parents' marriage is unstable, long school closure durations can lead to more difficulty in learning for the child [10]. In the longer term, the more likely the child will be to drop out. Also, students who rely on the free lunch served at school can face related problems [10].

Closing childcare programs or kindergarten schools could cause serious financial implications for these institutions and their employees [31]. Many childcare programs are small business operations or are run by faith-based institutions. Closing these programs because of a pandemic could lead to longterm interruption in the provision of such services.

Although there is evidence that school closures can mitigate the scope of an epidemic, they have substantial impact on the economy of a society, including the enormous cost of lost 
productivity due to parental absence from work [30]. For parents who cannot quit their jobs, this situation can cause distress. The impact of school closures, thus, will vary depending on socioeconomic factors and the home environment. If the school closure were to last 3 months, $93 \%$ of low-income households would be faced with serious financial problems as opposed to $64 \%$ of high-income households [34]. This proportion drops to $84 \%$ and $37 \%$, respectively, if people stay home for 1 month. One UK study found that about $1 \%$ of the UK gross domestic product could be affected by a 12-week school closure [35]. Using a stochastic individual-level model to simulate severe pandemic influenza in the United States, it was found that total costs of strategies involving school closures for 26 weeks was approximately 14 to 21 times more compared with the single intervention strategies of prevaccination or full-targeted antiviral post-exposure prophylaxis [36]. This finding indicates that strategies that involve school closures can reduce the US gross domestic product by $6.0 \%$.

\section{SCHOOL CLOSURE-ASSOCIATED MENTAL HEALTH ISSUES AMONG CHILDREN}

Through the assessment of national-level preparedness for epidemic and pandemic outbreaks, researchers developed an epidemic preparedness index (EPI). The EPI consists of five sub-indices measuring the economic resources, public health communications, infrastructure, public health systems, and institutional capacity of countries [37]. Although the EPI provides global comparative standards, it does not consider pandemic-specific and age-specific factors. There is very little mental health data on the school closures that can occur during a pandemic, compared with disasters caused by terrorism or traffic accidents. To the best of the author's knowledge, this is the first review on children's mental health to examine school closures during pandemics. Three topics regarding children's mental health and school closures were examined in order to support children's development during and after the COVID-19 outbreak: fear management, misinformation control, and strengthening resilience (Fig. 1).

Infectious diseases can cause fear and anxiety among children. Parents can relieve their children's fears and anxieties by explaining COVID-19 to them in terms they can understand [8]. Stress can build up when children have to stay at home and playing outside is banned because of a situation such as a pandemic [32]. Indoor physical activities that allow families to relax together are helpful. Parents should help children to maintain a regular daily life with activities they can perform indoors. If a family member or a relative is diagnosed with a pandemic disease, the stress in the family increases. If

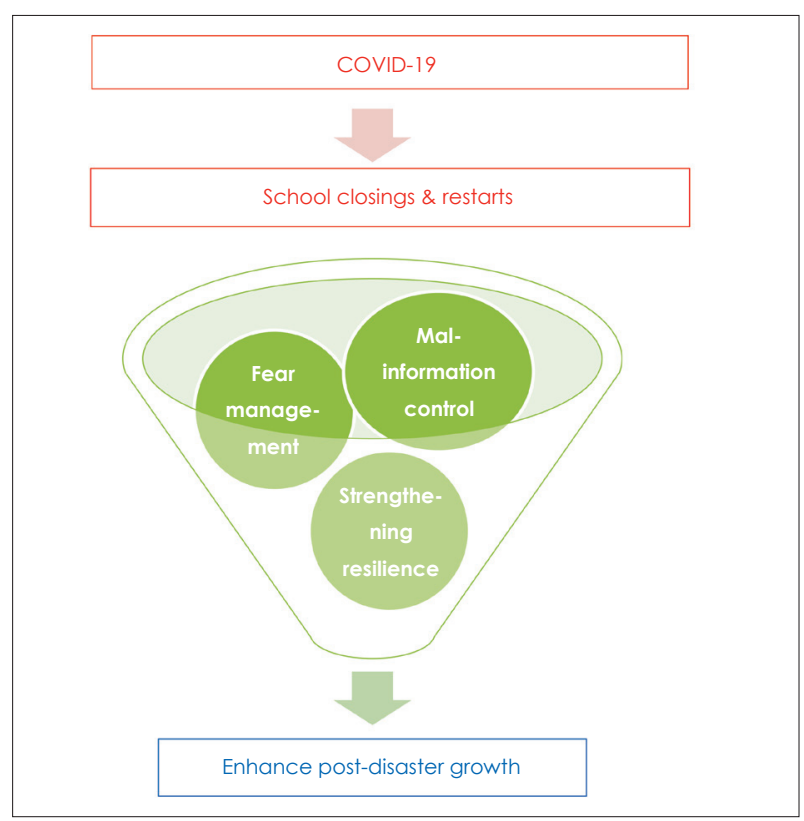

Fig. 1. Role of child mental health professionals during pandemic and related school closures. COVID-19: coronavirus disease 2019.

a child or a parent is hospitalized and confirmed as having COVID-19, anxiety can increase because of family isolation. Depending on the child's situation, counseling or short-term psychotherapy may be helpful [8]. Assessment for acute stress disorder or posttraumatic stress disorder may be required in cases of severe fear or anxiety. Guidelines provided by government agencies and expert organizations offer useful information for treating anxiety $[8,9]$.

The internet has a considerable amount of misinformation about COVID-19, including fake news. Children will be vulnerable to such exaggerated news and misinformation because they do not have enough knowledge or the capacity to differentiate between fact and fiction [11]. If contents from the media, including the social networking service (SNS), are not managed properly, the risk for chaos and the likelihood of a surge of fear among the population regarding medical care facilities will be heightened. Misinformation and fear can lead to discrimination and stigmatization. This may lead to children rejecting or avoiding proper medical interventions. Parents should evaluate the information their children are receiving about COVID-19 on social media and internet websites [9]. Mental health professionals frequently update COVID-19 information through the SNS or the websites of expert groups to minimize damage due to misinformation.

The purpose of the school closures is to prevent the spread of the pandemic and to protect children from the virus. However, school closings can hinder the healthy development of children [10]. Closing schools deprives children of schoolbased peer interactions and their daily routine. That is, in ad- 
dition to being psychologically and physically vulnerable during the pandemic, the children will also experience disruptions in their development or delays in their educational progress [38]. Parents should help children who have to stay at home to create a daily routine at home, and also allow the use of SNS or smartphones so that children with limited outdoor activities can communicate with their friends [9]. Children need resilience to restore pre-disaster levels of function and psychological equilibrium [11]. Improvements in access to resources, the encouragement of participation, and equitable treatment are required in order to promote children's resilience to disasters [38]. Support and cooperation from families and communities are also needed. As a method of promoting strength, parents should spend more leisure time with their children than usual. Strengthening resilience can promote post-disaster growth [11]. Future research should examine the factors mediating the potential for post-disaster growth that are related to COVID-19 and school closures, especially during children's developmental period.

The members of the Korean Academy of Child and Adolescent Psychiatry have gained much experience in the field of disaster psychiatry through several serious incidents, including a single incident of death witnessed by fourth graders at an elementary school in 2007 [39], suicidal death among elementary school students from 2011 to 2015 [40], and the Sewol Ferry disaster of 2014 [41]. The academy organized a new committee for disaster and trauma, and the committee created guidelines on the COVID-19 outbreak, including "Coping with the stress of COVID-19 epidemic: tips for families getting through school closing period" [42] and "Tips for adolescents: Coping with the stress of COVID-19 epidemic" [43]. The guidelines were published in Korean and English for use by the general public immediately after the COVID-19 outbreak.

\section{CONCLUSIONS}

Infants and children are vulnerable to diseases and, therefore, society must develop measures to protect them in the event of an epidemic such as COVID-19. Infectious disease management personnel should establish a system to cooperate with educational institutions, hospitals, medical personnel, nurseries for infants and toddlers, and mental health service providers. Unexpectedly, the COVID-19 outbreak has lasted for months and has extended to many people and many countries, prompting an unprecedented nationwide order of daycare centers; elementary, middle, and high schools; and colleges to close. Mental health professionals should prepare for patients with mental health problems related to long school closures and the reopening of schools. They should also pre- dict and take countermeasures against any problems that may arise in the near future and in the long run.

\section{Acknowledgments}

None.

\section{Conflicts of Interest}

The author has no potential conflicts of interest to disclose.

\section{ORCID iD}

Geon Ho Bahn https://orcid.org/0000-0002-3550-0422

\section{REFERENCES}

1) Wang C, Horby PW, Hayden FG, Gao GF. A novel coronavirus outbreak of global health concern. Lancet 2020;395:470-473.

2) Lake MA. What we know so far: COVID-19 current clinical knowledge and research. Clin Med (Lond) 2020;20:124-127.

3) Mak IW, Chu CM, Pan PC, Yiu MG, Chan VL. Long-term psychiatric morbidities among SARS survivors. Gen Hosp Psychiatry 2009;31:318-326.

4) Lee SM, Kang WS, Cho AR, Kim T, Park JK. Psychological impact of the 2015 MERS outbreak on hospital workers and quarantined hemodialysis patients. Compr Psychiatry 2018;87:123-127.

5) Xiang YT, Yang Y, Li W, Zhang L, Zhang $Q$, Cheung T, et al. Timely mental health care for the 2019 novel coronavirus outbreak is urgently needed. Lancet Psychiatry 2020;7:228-229.

6) Kang L, Li Y, Hu S, Chen M, Yang C, Yang BX, et al. The mental health of medical workers in Wuhan, China dealing with the 2019 novel coronavirus. Lancet Psychiatry 2020;7:e14.

7) Park SC, Park YC. Mental health care measures in response to the 2019 novel coronavirus outbreak in Korea. Psychiatry Investig 2020;17:85-86.

8) Centers for Disease Control and Prevention. Coronavirus Disease 2019 (COVID-19) [cited 2020 Mar 7]. Available from URL: https:// www.cdc.gov/coronavirus/2019-ncov/about/transmission.html.

9) Korean Neuropsychiatric Association. Mental health guideline for the psychological protection from COVID-19 [cited 2020 Mar 8]. Available from URL: http://www.knpa.or.kr/.

10) Cauchemez S, Van Kerkhove MD, Archer BN, Cetron M, Cowling BJ, Grove P, et al. School closures during the 2009 influenza pandemic: national and local experiences. BMC Infect Dis 2014;14: 207.

11) Shaw JA, Espinel Z, Shulz JM. Care of children exposed to the traumatic effects of disaster. Washington, DC: American Psychiatric Publishing;2012.

12) Comer JS, Fan B, Duarte CS, Wu P, Musa GJ, Mandell DJ, et al. Attack-related life disruption and child psychopathology in New York City public schoolchildren 6-months post-9/11. J Clin Child Adolesc Psychol 2010;39:460-469.

13) Mann M, Li J, Farfel MR, Maslow CB, Osahan S, Stellman SD. Adolescent behavior and PTSD 6-7 years after the World Trade Center terrorist attacks of September 11, 2001. Disaster Health 2015;2: 121-129.

14) Maunder R, Hunter J, Vincent L, Bennett J, Peladeau N, Leszcz M, et al. The immediate psychological and occupational impact of the 2003 SARS outbreak in a teaching hospital. CMAJ 2003;168: 1245-1251.

15) Donenberg GR, Pao M. Youths and HIV/AIDS: psychiatry's role in a changing epidemic. J Am Acad Child Adolesc Psychiatry 2005; 44:728-747.

16) Liu S, Yang L, Zhang C, Xiang YT, Liu Z, Hu S, et al. Online mental health services in China during the COVID-19 outbreak. Lancet Psychiatry 2020;7:e17-e18.

17) Cauchemez S, Valleron AJ, Boëlle PY, Flahault A, Ferguson NM. 
Estimating the impact of school closure on influenza transmission from Sentinel data. Nature 2008;452:750-754.

18) Caley P, Philp DJ, McCracken K. Quantifying social distancing arising from pandemic influenza. J R Soc Interface 2008;5:631639.

19) Glass RJ, Glass LM, Beyeler WE, Min HJ. Targeted social distancing design for pandemic influenza. Emerg Infect Dis 2006;12: 1671-1681.

20) Lo JY, Tsang TH, Leung YH, Yeung EY, Wu T, Lim WW. Respiratory infections during SARS outbreak, Hong Kong, 2003. Emerg Infect Dis 2005;11:1738-1741.

21) Hens N, Ayele GM, Goeyvaerts N, Aerts M, Mossong J, Edmunds JW, et al. Estimating the impact of school closure on social mixing behaviour and the transmission of close contact infections in eight European countries. BMC Infect Dis 2009;9:187.

22) Kawaguchi R, Miyazono M, Noda T, Takayama $Y$, Sasai $Y$, Iso $H$. Influenza (H1N1) 2009 outbreak and school closure, Osaka Prefecture, Japan. Emerg Infect Dis 2009;15:1685.

23) Earn DJ, He D, Loeb MB, Fonseca K, Lee BE, Dushoff J. Effects of school closure on incidence of pandemic influenza in Alberta, Canada. Ann Intern Med 2012;156:173-181.

24) Chen WC, Huang AS, Chuang JH, Chiu CC, Kuo HS. Social and economic impact of school closure resulting from pandemic influenza A/H1N1. J Infect 2011;62:200-203.

25) Johnson AJ, Moore ZS, Edelson PJ, Kinnane L, Davies M, Shay DK, et al. Household responses to school closure resulting from outbreak of influenza B, North Carolina. Emerg Infect Dis 2008; 14:1024-1030.

26) Rodriguez CV, Rietberg K, Baer A, Kwan-Gett T, Duchin J. Association between school closure and subsequent absenteeism during a seasonal influenza epidemic. Epidemiology 2009;20:787-792.

27) Chen Y, Badaruddin H, Lee VJ, Cutter J, Cook AR. The effect of school closure on hand, foot, and mouth disease transmission in Singapore: a modeling approach. Am J Trop Med Hyg 2018;99: $1625-1632$

28) Ryu S, Chun BC; Korean Society of Epidemiology 2019-nCoV Task Force Team. An interim review of the epidemiological characteristics of 2019 novel coronavirus. Epidemiol Health 2020;42:e2020006.

29) Li Q, Guan X, Wu P, Wang X, Zhou L, Tong Y, et al. Early transmission dynamics in Wuhan, China, of novel coronavirus-infected pneumonia. N Engl J Med 2020 Jan 29 [Epub]. Available from URL: https://doi.org/10.1056/NEJMoa2001316.

30) Xue Y, Kristiansen IS, de Blasio BF. Dynamic modelling of costs and health consequences of school closure during an influenza pandemic. BMC Public Health 2012;12:962.

31) Stevenson E, Barrios L, Cordell R, Delozier D, Gorman S, Koenig
LJ, et al. Pandemic influenza planning: addressing the needs of children. Am J Public Health 2009;99 Suppl 2:S255-S260.

32) Bradley RH; National Institute of Child Health and Human Development (NICHD) Early Child Care Research Network. Child care and common communicable illnesses in children aged 37 to 54 months. Arch Pediatr Adolesc Med 2003;157:196-200.

33) Yonhap News. Government to extend child care hours as virus outbreak continues. The Korea Herald 2020 March 6. Available from URL: http://www.koreaherald.com/view.php?ud=20200306000569.

34) Blendon RJ, Koonin LM, Benson JM, Cetron MS, Pollard WE, Mitchell EW, et al. Public response to community mitigation measures for pandemic influenza. Emerg Infect Dis 2008;14:778-786.

35) Sadique MZ, Adams EJ, Edmunds WJ. Estimating the costs of school closure for mitigating an influenza pandemic. BMC Public Health 2008;8:135.

36) Sander B, Nizam A, Garrison LP Jr, Postma MJ, Halloran ME, Longini IM Jr. Economic evaluation of influenza pandemic mitigation strategies in the United States using a stochastic microsimulation transmission model. Value Health 2009;12:226-233.

37) Oppenheim B, Gallivan M, Madhav NK, Brown N, Serhiyenko V, Wolfe ND, et al. Assessing global preparedness for the next pandemic: development and application of an Epidemic Preparedness Index. BMJ Glob Health 2019;4:e01157.

38) Peek L. Children and disasters: understanding vulnerability, developing capacities, and promoting resilience-an introduction. Child Youth Environ 2008;18:1-29.

39) Song SH, Kim BN, Choi NH, Ryu J, McDermott B, Cobham V, et al. A 30-month prospective follow-up study of psychological symptoms, psychiatric diagnoses, and their effects on quality of life in children witnessing a single incident of death at school. J Clin Psychiatry 2012;73:e594-e600.

40) Hong M, Cho HN, Kim AR, Hong HJ, Kweon YS. Suicidal deaths in elementary school students in Korea. Child Adolesc Psychiatry Ment Health 2017;11:53.

41) Lee M, Hwang J, Bhang S. A qualitative study on the process of the mental health assessment and intervention after the Sewol Ferry disaster: focusing on survivors among Danwon High School students. J Korean Acad Child Adolesc Psychiatry 2018;29:161-171.

42) The Korean Academy of Child and Adolescent Psychiatry. Coping with the stress of COVID-19 epidemic. Tips for families: getting through school closing period [cited 2020 Mar 8]. Available from URL: http://kacap.or.kr.

43) The Korean Academy of Child and Adolescent Psychiatry. Tips for adolescents: coping with the stress of COVID-19 epidemic [cited 2020 Mar 8]. Available from URL: http://kacap.or.kr. 